tion to the large increase in the German capacity to produce synthetic nitrogen compounds, and the erection of new plants in that country. At the end of this year Germany will be independent of all importation of nitrates, while the large munition works in this country are being dismantled. The subject, therefore, has political importance as well as scientific and commercial interest.

Mr. J. H. West's paper dealt with the manufacture of the nitrogen and hydrogen required for synthetic ammonia processes. Three volumes of hydrogen being required for one of nitrogen, and the former being the more expensive gas, the cost of the process depends mainly on that of the hydrogen. The electrolytic process is convenient, and yields pure hydrogen, but the capital cost of the plant is high, and the method is only practicable where cheap hydro-electric power is available. Coke oven gas may be used, the method employed being that of liquefying all the gases present except hydrogen, but in this case the small quantity of carbon monoxide which always remains mixed with it must be removed by chemical washing or by conversion into methane, the gas being a poison to the catalyst in the subsequent ammonia synthesis. Water gas may be used, a reaction with steam being brought about in presence of a catalyst : $\mathrm{CO}+\mathrm{H}_{2} \mathrm{O}=\mathrm{CO}_{2}+\mathrm{H}_{2}$. In a modified process, due to the author and $\mathrm{A}$. Jacques, the coal is treated by a process of complete gasification, and the gaseous products treated in the same apparatus to yield carbon dioxide and hydrogen with a catalyst. Nitrogen is made by the liquid air process, or by mixing air and hydrogen in such proportions that on passing over a suitable catalyst the oxygen is converted to water, and a mixture of nitrogen and hydrogen in the required proportions remains. In. the Haber process, water gas and producer gas are mixed in such proportions that a correct mixture is left after removal of the carbon monoxide.

Both this paper, and the succeeding one by Mr. C. $J$. Goodwin, were presented in the absence of their authors, so that they suffered in the discussion. $\mathrm{Mr}$. Goodwin described the Häusser process for the production of nitric acid by exploding nitrogen and oxygen with a fuel gas in a bomb. Although the plant has hitherto been on an experimental scale, it is expected that the new bombs of $1200-1500$ litres capacity will give commercial yields, and the use of stainless steel has overcome much of the corrosion difficulty. The absorption towers have been greatly reduced in size by employing nickel-chromium steel or siliconiron for the vessels, under a pressure of $2 \cdot 5-4$ atmospheres. The suggestion has been made that a special gas engine or Humphrey pump might be used in place of a bomb, in order to utilise the heat energy of the fuel more economically, but it remains to be seen whether such a change would prove advantageous on the whole. The main advantage of the process is its compactness, the size of the plant being small, especially when gases of high calorific value are used.

Dr. E. B. Maxted's contribution concerned the question whether nitrogen fixation, based on water power, could be economically undertaken in this country. Under present conditions, there are several sites in these islands where it should be possible to produce hydro-electric energy for $4 l .-5 l$. per kilowattyear, the greater part of this sum representing interest on the capital cost. This would allow of the production of electrolytic hydrogen at a cost of $1 s .7 d$. per Iooo cubic feet, which does not compare unfavourably with the cost of hydrogen from fuel. Greater economy would be effected if uses for large supplies of oxygen in the chemical industries could be found. Comparing together the ammonia and cyanamide processes, it appears that a given amount of power, say 10,000 kilowatts, being available, either process would result in the fixation of about the same quantity of nitrogen, but the ammonia process would yield large quantities of oxygen as a by-product, while the cyanamide process would require the bringing of anthracite and lime to the site. There would be some compensating conditions, such as the greater simplicity of the cyanamide process, and the necessity of fixing ammonia by means of an acid.

Mr. E. Kilburn Scott denied the contention that the arc process is uneconomical. It has been stated that in Norway nitric acid could be made profitably where electric energy costs Iol. per kilowatt-year, while the Scottish schemes can provide the same quantity for $4 l$. The arc process is the only one capable of utilising off-peak power, and where large generating stations are set up it is quite economical. Moreover, calcium nitrate is the best of all artificial fertilisers. Little else emerged in the discussion. It is clear that processes which promised well during the exceptional conditions of the war have to be re-examined very carefully in regard to their practicability under ordinary conditions of competition, and it has yet to be demonstrated that synthetic processes can be established successfully where power has to be obtained from the combustion of coal. Whatever may prove to be the future of these processes, Dr. Harker's review of the present position of the question will be of value, as an addition to the important memoirs already published from official sources.

\title{
The Thermal Basis of Gas Supply.
}

\author{
By Prof. Jонn W. Совв.
}

$\mathrm{T}^{\mathrm{H}}$ HE amount of attention which has been given in the Press during the past few months to the new basis of charge for gas introduced by the Gas Regulation Act of 1920 , is at first sight somewhat surprising and unexpected. To the scientific mind there seems to be so little in it that calls for mental strain in its comprehension, or for criticism in its introduction.

Gas is now to be sold at so much per therm, and the therm is simply 100,000 British Thermal Unitsi.e. a convenient multiple of what is the most widely known and generally accepted unit of heat. A 
decision having once been taken to charge for gas on a thermal basis, the choice of such a unit was natural if not inevitable. It is true that the justice of making the potential heat units in the gas the sole measure of its usefulness is not to be established completely by a priori considerations, although most of us would probably be inclined to look kindly upon the notion from the beginning. There are factors other than potential heat content which might help to determine the value of gas in use, and should, therefore, be considered, such as the temperature attainable on combustion. If these factors were of sufficient importance the assumption that thermal units alone could be rightly taken as determining price would be invalid and a different basis for charging necessary.

Such matters as these were, however, discussed at length in conferences called by Sir George Beilby for the purpose, before the Fuel Research Board made the recommendations to the Board of Trade on which the Act was based. At these conferences the experience and the judgment of gas users and makers were freely drawn upon, and the results of experimental work bearing directly upon the points at issue, made by the Joint Research Committee of the University of Leeds and the Institution of Gas Engineers, were considered. The result was an acceptance by all parties of the principle establishing a thermal basis for the sale of gas. It was accepted that the legislative control of the gas industry, necessary because it is a public service with certain exclusive rights, must be made more elastic in some fundamental respects if the gas industry was to be able to take advantage of technical developments presented to it, and to realise fuel and monetary economies, so obviously desirable at the present time for the public good and its own interests.

The magnitude of that industry and the national importance of improvements effected in it may easily escape notice. The gas industry does not dominate any particular town or locality in the same way that steel dominates Sheffield or Middlesborough, or cotton some of the Lancashire towns, but in estimating the importance of the industry it should be remembered that every city and town and many a village throughout the country has its gasworks, carbonising a total of eighteen million tons of coal per annum, and incidentally employing a capital of some 150 million pounds.

The greater elasticity of control to which reference has been made above included a permission to each company or authority to supply gas of the calorific value which it could produce most economically, although the calorific value being declared a close adherence to the standard was to be secured by systematic outside inspection and testing, in which the recording gas calorimeter was to play a prominent part. On this system one town may be supplying gas of $55^{\circ}$ British Thermal Units per cubic foot, and another a $45^{\circ}$ gas. Comparison of charges cannot be made fairly on the price per rooo cu. ft. alone, but requires a correction for calorific value. Charging by the therm, i.e. by the potential heat units carried by the gas, simplified the matter by introducing a common denominator.

To. Sir George Beilby and others, including the writer, there seemed to be no difficulty in such a change or objection to it from the consumer's point of view. In justice to the gas industry it may be said that when the matter was under discussion its representatives declared themselves as being apprehensive of the way in which this strange new mode of making out a gas bill would be viewed by some consumers, and, through the ministrations of a certain section of the Press, this apprehension seems to have been justified for the time being.

An explanatory pamphlet bearing "The Therm " 1 as its title has just been issued by the Department of Scientific and Industrial Research (to which the Fuel Research Board is attached) in which the reports of the Fuel Research Board on "Gas Standards" have been reprinted. It is issued at a very low price, presumably with the hope of securing many readers and of placing the public in a less confused state of mind on a question in which a large section has a very direct interest.

There is something to be said for this hope. The only fear is that these reports, although well and clearly written, are somewhat too technical in content and language for the layman. Moreover, although this does not affect the main issue, one disadvantage arises from the fact that although the operative Act is based upon the recommendations of the Fuel Research Board as detailed in the pamphlet, there are some points of difference between the two which might have been indicated.

But it is surely plain enough, answering the question usually asked, that no increase in a gas bill can be rightly attributed to the use of the therm as the basis of charge. If a consumer has burned $2000 \mathrm{cu}$. $\mathrm{ft}$. of gas with a calorific value of 500 British Thermal Units per cu. ft. he has used ro therms, and it is a matter of indifference whether he is charged $4 s .2 d$. per Iooo cu. ft. or Iod. per therm; the same volume and calorific value determine the sum in each case and he pays Iood.

It is true that according to the Act, when a gassupplying company or authority comes under the new scheme an increase in price may be authorised by the Board of Trade " in order to meet unavoidable increases since the 3 oth day of June I9I4 in the costs and charges of, and incidental to, the production and supply of gas by the undertakers," but that is another matter, and has nothing to do with the use of the therm as the unit of measurement.

Moreover, although it is possible such increase of price may be authorised as essential, in some cases and for the time being, to the stability of a service which must be maintained in the public interest, it is widely recognised inside and outside the gas industry that the full development of public gas supply, with all the undoubted benefits it can confer upon the community, can be attained only through the medium of a cheaper gas. In the opinion of the writer it is also true that, in spite of misleading indications of the moment, the Gas Act of I920 with its thermal basis of charge is well calculated to stimulate a continuous and general movement in that direction which will become more apparent in the future.

1 The Therm. Reports of the Fuel Research Board on Gas Standards. (London: Stationery Office, 1922.) $3 d$. net.

\section{NO. 2768 , VOL. I IO}

